\title{
NOVOS TÁXONS NEOTROPICAIS DE DESMIPHORINI (COLEOPTERA, CERAMBYCIDAE, LAMIINAE)
}

\author{
Maria Helena M. Galileo ${ }^{1,3}$ \\ Ubirajara R. Martins ${ }^{2,3}$
}

\begin{abstract}
NEW TAXA OF NEOTROPICAL DESMIPHORINI (COLEOPTERA, CERAMBYCIDAE, LAMIINAE). New species described from Brazil: Curuapira tuberosa (Espírito Santo); Stereomerus maculatus (Bahia); Gyrpanetes oryba (Espírito Santo); Desmiphora (D.) santossilvai (Pará); Desmiphora (D.) uniformis (Bahia). Icublabia gen. nov., type-species, I. multispinosa sp. nov. from Ecuador (Napo) are described. Curuapira exotica Martins \& Galileo, 1998, originally described from Venezuela, is recorded from Brazil (Amazonas, Rondônia and Mato Grosso).
\end{abstract}

KEYWORDS. Cerambycidae, Coleoptera, Desmiphorini, Lamiinae, taxonomy.

\section{INTRODUÇÃO}

A tribo Desmiphorini foi objeto de revisão por Breuning (1974). MARTins \& GALILEO (1998) apresentaram uma chave para identificação dos gêneros com protórax desarmado nos lados e descreveram novos táxons em diversas contribuições (Martins \& Galileo, 1997; GALILEO \& MarTins, 1998a,b, 1999).

Com base em material pertencente principalmente ao Museu Nacional, Universidade Federal do Rio de Janeiro (MNRJ), apresentamos a ampliação da distribuição de Curuapira exotica Martins \& Galileo, 1998, descrita originalmente da Venezuela, para o Brasil (Amazonas, Rondônia e Mato Grosso) e acrescentamos uma segunda espécie ao gênero Curuapira. São descritas espécies nos gêneros Stereomerus Melzer, 1934, Gyrpanetes Martins \& Galileo, 1998 e Desmiphora Audinet-Serville, 1835. Um novo gênero para o Equador (Napo) é proposto, espécie-tipo Icublabia multispinosa sp. nov., coletada a 2000 metros de altitude e pertencente ao Canadian Museum of Nature, Ottawa (CMNO). Mencionamos ainda material pertencente ao Museu de Ciências Naturais, Fundação Zoobotânica do Rio Grande do Sul, Porto Alegre (MCNZ) e ao Museu de Zoologia, Universidade de São Paulo, São Paulo (MZSP).

1. Museu de Ciências Naturais, Fundação Zoobotânica do Rio Grande do Sul, Caixa Postal 1188, 90001-970 Porto Alegre, RS, Brasil.

2. Museu de Zoologia, Universidade de São Paulo, Caixa Postal 42594, 04299-970 São Paulo, SP, Brasil.

3. Bolsista do CNPq. 


\section{Curuapira exotica Martins \& Galileo, 1998}

Curuapira exotica Martins \& Galileo, 1998:263, fig. 4.

Descrita originalmente da Venezuela (Aragua) com base num macho. Registramos agora para o Brasil, Amazonas, Rondônia e Mato Grosso.

Material examinado. BRASIL, Amazonas: Manaus (Reserva Ducke, $26 \mathrm{~km} \mathrm{NE}$ ), 3 , 15.VIII.1995, J. C. G. Hurtado col., com choque de inseticida em Micropholis guyanensis (A. DC.) Pierre, Sapotaceae (MZSP); Rondônia: Ouro Preto do Oeste, 5 \&, 4 f, X.1983, Becker, Roppa \& Silva col. (MNRJ, MCNZ, MZSP); 2 †, XI.1983, Roppa, Becker \& Silva col. (MNRJ); హ, ㅇ, XII.1983, B. Silva col. (MNRJ). Mato Grosso: Sinop (12 $31^{\prime} \mathrm{S}, 55^{\circ} 37^{\prime} \mathrm{W}$, rodovia BR-163, km 500-600, 350 m), 2 ㅇ, X.1974, Alvarenga \& Roppa col. (MNRJ); హ, IX.1974, Alvarenga \& Roppa col. (MNRJ).

Procedência a confirmar: BRASIL, São Paulo: Teodoro Sampaio, ơ, XI.1972, Col. Fragoso (MNRJ).

\section{Curuapira tuberosa sp. nov.}

(Fig. 1)

Tegumento avermelhado, mais acastanhado na cabeça. Lobos oculares superiores com 5-6 fileiras de omatídios distantes entre si quanto o dobro da largura de um lobo. Antenas dos machos atingem o ápice dos élitros na extremidade do antenômero IX; das fêmeas, no ápice do X. Escapo engrossado para a ponta, com asperezas no lado externo do terço apical. Protórax tão largo quanto longo; lados com gibosidade grande no meio. Pronoto densamente pubescente, com dois tubérculos bem projetados à frente do meio; uma gibosidade pouco notável, no meio e atrás das anteriores; sulco transversal à frente da orla basal bem demarcado. Processo prosternal com pêlos brancos abundantes nos dois sexos. Élitros (fig. 1) com uma grande área basal de pubescência branco-amarelada, oblíqua das margens para a sutura, que vai até o meio; restante do élitro revestida por pubescência avermelhada curta, exceto mancha apical, alongada, de pubescência esbranquiçada, que ocupa o quarto apical. Élitros sem setas. Fêmures mais robustos nos machos do que nas fêmeas. Tíbias grossas com pêlos curtos, pretos, nos dois terços apicais. Face ventral do corpo revestida por pubescência esbranquiçada.

Dimensões, em mm, respectivamente $3 /$ f. Comprimento total 14,7/8,5-12,7; protórax: comprimento 3,0/1,6-2,5, maior largura 3,1/1,8-2,8; comprimento do élitro 10,3/6,2-9,3; largura umeral 4,2/2,4-3,7.

Material-tipo. Holótipo ơ, BRASIL, Espírito Santo: Linhares, X.1972, B. Silva col. (MNRJ). Parátipos: Linhares (Parque Sooretama),, , XII.1962, F. M. Oliveira col. (MZSP); 2 , X.1967, F. M. Oliveira col. (MCNZ, MNRJ); Pedro Canário (Conceição da Barra), ఢ, X.1962, Oliveira \& Roppa col. (MNRJ).

Discussão. Curuapira tuberosa difere de C. exotica: pelos lobos oculares superiores tão afastados entre si quanto o dobro da largura de um lobo; pelos dois tubérculos muito projetados no pronoto; pela mancha apical de pubescência branca nos élitros. Em C. exotica os lobos oculares superiores estão separados entre si por distância igual à largura de um lobo; o pronoto não apresenta tubérculos e a região apical dos élitros é destituída de pubescência branca.

\section{Stereomerus maculatus sp. nov.}

(Fig. 2)

Cabeça com tegumento preto revestido por pubescência amarelada. Fronte mais longa do que larga com lados levemente divergentes para a parte inferior. Lobos oculares 
superiores mais próximos entre si do que o diâmetro de um lobo; lobos oculares inferiores mais longos do que as genas. Antenas com o dobro do comprimento do corpo. Escapo pedunculado e clavado, pouco mais curto do que o antenômero III. Antenômeros IV a XI com comprimento ligeiramente decrescente.

Pronoto preto com pubescência amarelada; em duas áreas longitudinais látero-anteriores, com pubescência mais esparsa; numerosos pontos pequenos, moderadamente densos. Lados do protórax com tubérculo no nível do terço basal. Processo prosternal com tubérculo arredondado e fortemente vertical. Mesepimero pontuado. Élitros (fig. 2) com tegumento avermelhado, recobertos por áreas irregulares, pequenas, de pubescência amarelada.
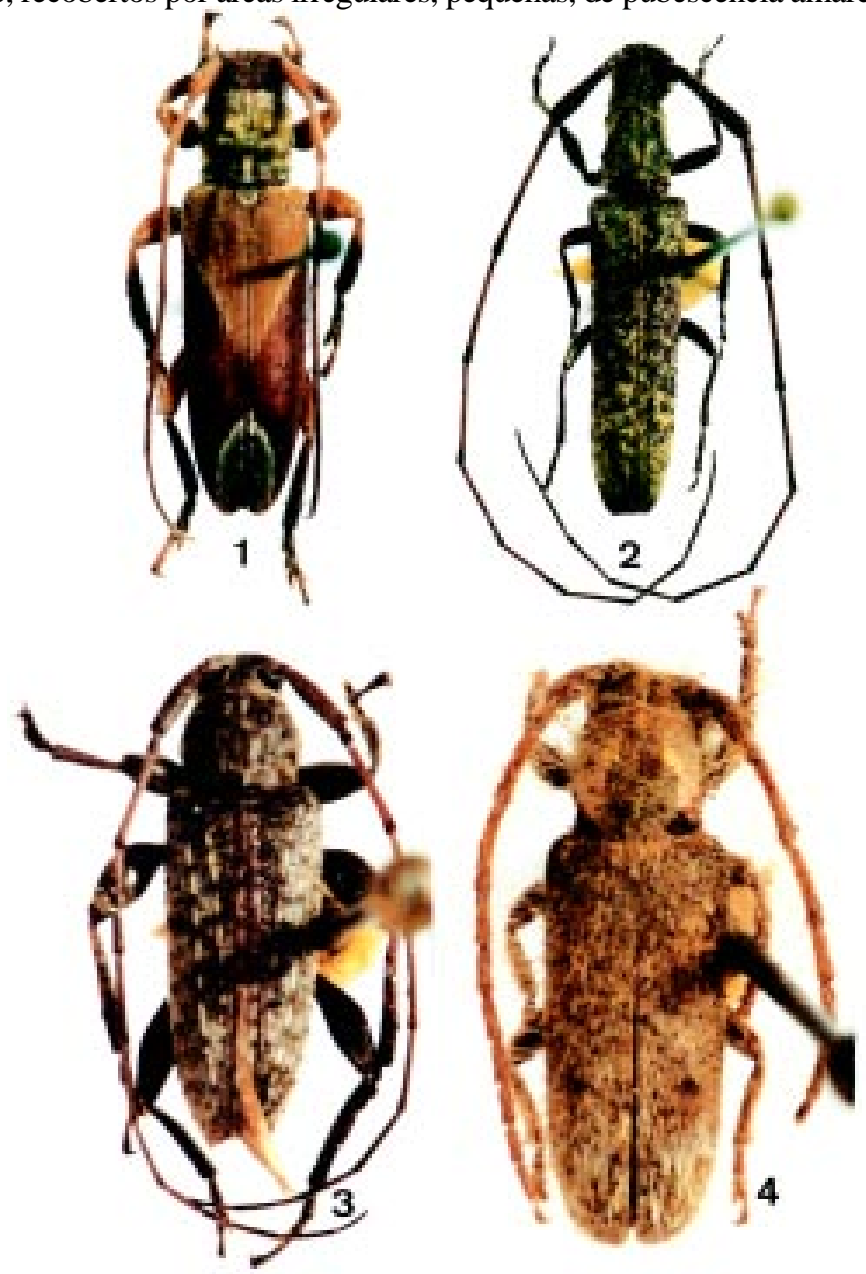

Figs. 1-4. 1, Curuapira tuberosa sp. nov., parátipo 9 , do Brasil (Espírito Santo), comprimento, 12,7 $\mathrm{mm} ; 2$, Stereomerus maculatus sp. nov., holótipo $\delta$, do Brasil (Bahia), comprimento, 10,8 mm; 3, Gyrpanetes oryba sp. nov., holótipo ₹, do Brasil (Espírito Santo), comprimento 6,7 mm; 4, Desmiphora (D.) uniformis sp. nov., holótipo $\subsetneq$, do Brasil (Bahia), comprimento $8,0 \mathrm{~mm}$. 
Dimensões, em mm. Comprimento total 10,8; comprimento e maior largura do protórax 1,8; comprimento do élitro 7,6; largura umeral 2,4.

Material-tipo. Holótipo ơ, BRASIL, Bahia: Cândido Sales, XI.1971, Seabra \& Roppa col. (MNRJ).

Discussão. Como na espécie-tipo, S. pachypezoides Melzer, 1934 (MARTins \& GaLILEO, 1994:6, figs. 9, 10), Stereomerus maculatus apresenta os metafêmures com depressão pubescente em quase toda a face ventral . Distingue-se de todas as demais espécies do gênero, com exceção de S. brachypterus Martins \& Galileo, 1994, pela pubescência elitral não distribuída em faixas longitudinais. Difere de $S$. brachypterus pela fronte mais longa do que larga e com lados divergentes; pelos lobos oculares superiores tão distantes entre si quanto a largura de um lobo; pelos tubérculos anteníferos projetados e pelo processo prosternal truncado, com tubérculo. Em S. brachypterus, conhecida de uma fêmea, a fronte é quadrangular, os lobos oculares superiores são tão distantes entre si quanto o dobro da largura de um lobo, os tubérculos anteníferos pouco projetados e o processo prosternal é regularmente curvo e sem tubérculo.

\section{Gyrpanetes oriba sp. nov.}

(Fig. 3)

Etimologia. Tupi, oryba $=$ alegre, alusivo ao colorido .

Tegumento castanho-avermelhado, mais avermelhado nas antenas e nos élitros. Fronte transversal revestida por pubescência esbranquiçada. Lobos oculares superiores com cinco fileiras de omatídios. Antenas, recobertas por pubescência esbranquiçada, atingem o ápice dos élitros aproximadamente na ponta do antenômero IX. Protórax avermelhado revestido por pubescência esbranquiçada, com cinco manchas pequenas de tegumento escuro revestidas por pubescência amarelada. Élitros (fig. 3) com região circum-escutelar não elevada, pubescência esbranquiçada, mais concentrada em duas faixas estreitas longitudinais: uma mais próxima da sutura que se estende desde próximo da base até o meio; outra mais externa, prolongada até o quinto apical; ambas interrompidas por pontos setíferos escuros. Ápices elitrais obliquamente truncados e projetados no ângulo externo. Fêmures acastanhados, revestidos por pubescência esbranquiçada e sem pêlos longos. Metatíbias acastanhadas com longos pêlos.

Dimensões, em mm. Comprimento total 6,7; protórax: comprimento 1,3, maior largura 1,7; comprimento do élitro 4,8; largura umeral 2,2.

Material-tipo. Holótipo ơ, BRASIL, Espírito Santo: Linhares, X.1972, B. Silva col. (MNRJ).

Discussão. Gyrpanetes oryba assemelha-se a G. cacapira Martins \& Galileo, 1998 pela região circum-escutelar dos élitros apenas elevada e pelas extremidades elitrais obliquamente truncadas com projeção no lado externo. Difere pelos élitros com faixas de pubescência branca, longitudinais e estreitas.

\section{Desmiphora (D.) santossilvai sp. nov.}

(Fig. 5)

Etimologia. O epíteto homenageia Antonio Santos Silva (MZSP), a quem devemos inúmeras gentilezas.

Tegumento alaranjado. Cabeça recoberta por pilosidade amarelada, mais esparsa na região inferior da fronte. Escapo com anel central de pubescência branca e pêlos abundantes, enegrecidos, no lado externo; pêlos brancos no lado interno. Flagelômeros 
com franja de pêlos longos e brancos. Antenômero III alongado e curvo. Pronoto com pincel de pêlos castanhos na margem anterior; centro do pronoto com dois pincéis de pêlos alaranjados; centro da margem basal do pronoto com pincel frouxo de pêlos pretos. Élitros (fig. 5) cobertos por pubescência amarelada e mais concentrada em áreas dispersas pela superfície. Cada élitro com quatro tufos de pêlos laranja: um, alongado, centrobasal; um pequeno, situado no lado externo do primeiro; um dorsal depois do meio e um na declividade apical. Lados dos élitros providos de pêlos longos, abundantes, alaranjados e brancos. Processo prosternal curvo. Processo mesosternal com tubérculo evidente. Fêmures alaranjados com mancha escura, pouco contrastante, no lado externo e perto do ápice, seguida por área coberta de pubescência esbranquiçada. Metepisternos avermelhados com friso marginal preto. Urosternitos avermelhados com mancha lateral preta.

Dimensões, em mm. Comprimento total 9,5; protórax: comprimento 2,2, maior largura do protórax 3,0; comprimento do élitro 7,0; largura umeral 3,5.

Material-tipo. Holótipo ₹, BRASIL, Pará: Jacareacanga, XII.1968, M. Alvarenga col. (MNRJ).

Discussão. Martins \& Galileo (2002) publicaram chave para as espécies de Desmiphora Audinet-Servile, 1835 com tubérculo no mesosterno, grupo ao qual pertence $D$. (D.) santossilvai. Élitros sem carena longitudinal, pontuados na metade anterior e a base de cada élitro com dois pincéis de pêlos castanho-avermelhados conduzem, na chave, a duas espécies: $D$. (D.) multicristata Bates, 1866 e $D$. (D.) tigrinata Martins \& Galileo, 2002. Desmiphora (D.) santossilvai, que também apresenta esse conjunto de caracteres, tem dois fascículos no pronoto e, portanto, é mais semelhante a $D$. $(D$.) multicristata. Esta espécie tem, na base de cada élitro, três fascículos de pêlos e para o ápice mais três pincéis de pêlos, todos "testaceo-fulvis" (BATES, 1866:201), posicionados

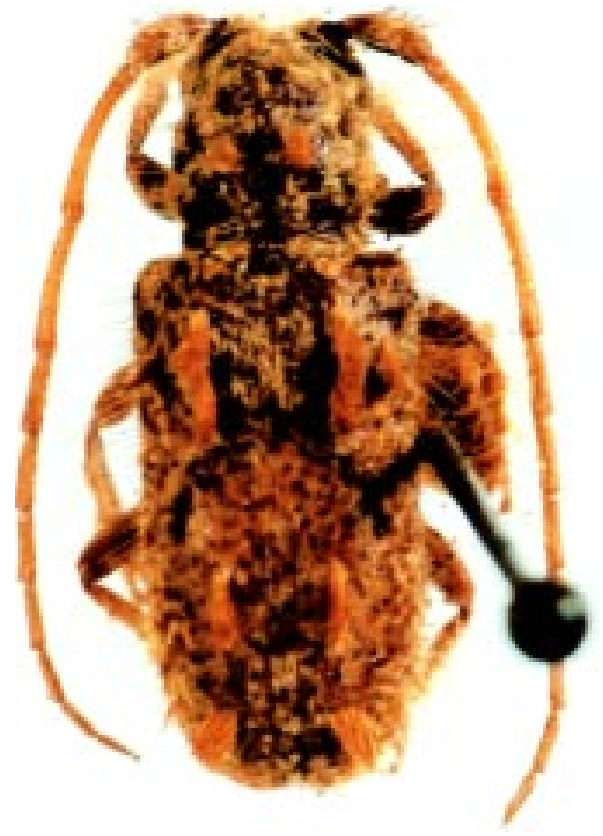

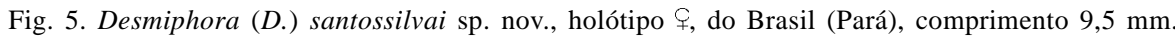


na mesma linha transversal e os lados do metasterno e os urosternitos basais pretos. Desmiphora $(D$.$) santossilvai tem na base de cada élitro somente dois fascículos: um no$ terço apical e um anteapical, todos alaranjados; a face ventral do corpo é avermelhada com os metepisternos escurecidos nas bordas e os últimos urosternitos com pequena mancha preta lateral.

\section{Desmiphora (D.) uniformis sp. nov.}

(Fig. 4)

Tegumento avermelhado, revestido por pubescência densa esbranquiçada. Vértice e borda anterior do pronoto sem tufos de pêlos. Lobos oculares superiores com cinco fileiras de omatídios. Antenômero III mais longo que o escapo. Lados do protórax com projeção diminuta. Pronoto com área látero-posterior de pubescência esbranquiçada mais concentrada, que termina, pouco à frente do meio, em pincel frouxo. Partes láterobasais do pronoto com pequenas áreas glabras, talvez pela pubescência mal-conservada. Élitros (fig. 4) com pubescência uniforme e com a metade basal sem tufos ou pincéis; na metade apical a pubescência é mais longa em duas áreas dorsais: uma ao nível do quarto apical e uma anteapical. Processos pro- e mesosternal sem tubérculos.

Dimensões, em mm. Comprimento total 8,0; protórax: comprimento 2,3, maior largura 2,0; comprimento do élitro 5,6; largura umeral 2,4.

Material-tipo. Holótipo ধ, BRASIL, Bahia: Maracás, II.1963, F. M. Oliveira col. (MNRJ).

Discussão. Desmiphora $(D$.$) uniformis não tem tubérculos nos pro- e mesosterno,$ a base e a metade apical dos élitros não apresentam pincel ou tufo de pêlos. Essa combinação de caracteres ocorre também em $D$. (D.) decora (Melzer, 1928), D. (D.) circumspecta (Lane, 1973) e $D$. (D.) niveocincta (Lane, 1959), espécies com abundantes áreas coloridas nos élitros. Considerando o pincel na metade apical dos élitros, $D .(D$. uniformis assemelha-se a $D$. (D.) longipilis (Fisher, 1926), ocorrente em Cuba, e $D$. (D.) mirim Martins \& Galileo, 2002 procedente do Amazonas, Brasil. Difere de D. (D.) mirim pela ausência de desenhos de pubescência branca no pronoto e nos élitros.

\section{Icublabia gen. nov.}

Espécie-tipo, Icublabia multispinosa sp. nov.

Etimologia. Tupi, icu = espinho; Blabia, gênero que mais se assemelha a Icublabia . Gênero gramatical feminino.

Fronte quadrangular. Tubérculos anteníferos projetados, distantes. Lobos oculares superiores com quatro fileiras de omatídios tão distantes entre si quanto o quádruplo da largura de um lobo; lobos oculares inferiores grandes, com o triplo do comprimento das genas. Antenas mais longas do que o corpo. Escapo delgado, subcilíndrico, sem cicatriz apical e, visto de perfil, curvo para o lado inferior perto do ápice; comprimento subigual ao do antenômero III. Antenômero III mais longo do que o IV. Antenômeros V-XI com comprimentos decrescentes. Protórax com espinho alongado e curvo para o lado superior; base posterior desse espinho com tubérculo. Pronoto com elevação transversal no meio. Élitros alongados com lados subparalelos; úmeros projetados em grande espinho dirigido para trás; par de espinhos dorsais no nível do quarto anterior; par de espinhos, laterais, no meio; par de espinhos, dorsais, no terço apical; élitros com tubérculos, brilhantes, pequenos e esparsos, principalmente ao longo da margem; extremidade elitral truncada 
com longo espinho divergente no lado externo. Fêmures delgados, apenas engrossados para os ápices. Tíbias finas. Metatarsômero I tão longo quanto II+III. Processo mesosternal sem tubérculo.

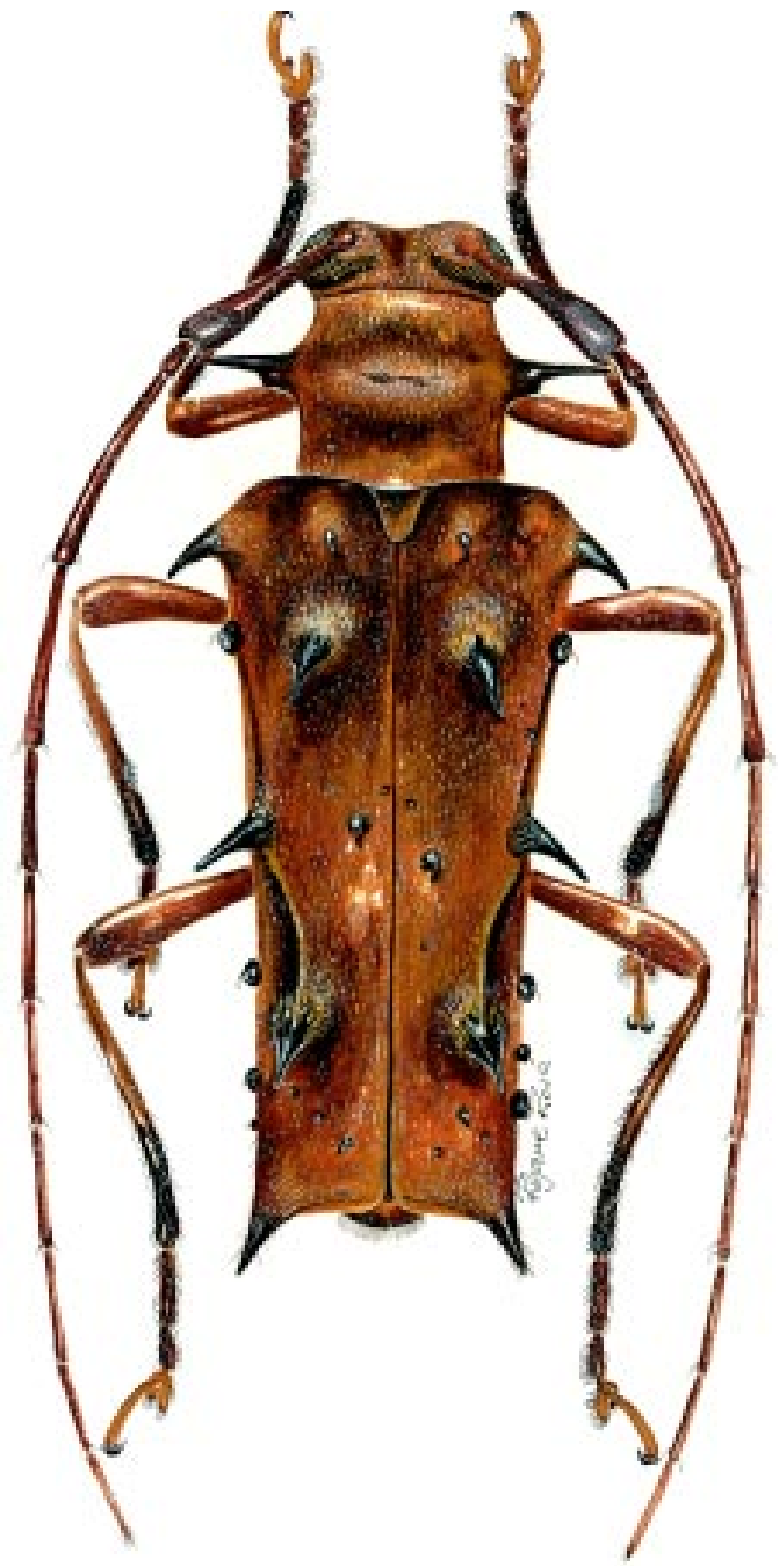

Fig. 6. Icublabia multispinosa sp. nov., holótipo $\subsetneq$, do Equador (Napo), comprimento 15,1 mm. 


\section{Icublabia multispinosa sp. nov.}

(Fig. 6)

Tegumento avermelhado; preto nos espinhos, tubérculos elitrais e ápices das tíbias. Pubescência amarelada em todo corpo; entre o espinho central e o do terço apical (fig. 6), uma linha de pubescência mais concentrada marginada, pelo lado externo, por faixa de tegumento preto. Pontuação elitral fina, moderadamente esparsa, na metade anterior dos élitros.

Dimensões, em mm. Comprimento total 15,1; protórax: comprimento 2,8, maior largura (espinhos inclusive) 5,2; comprimento do élitro 11,8; largura umeral (espinhos inclusive) 6,4

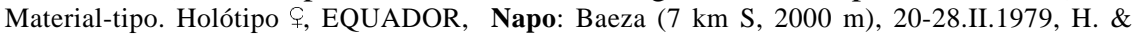
A. Howden col. (CMNO).

Discussão. Nenhum gênero de Desmiphorini pode ser comparado com Icublabia gen. nov., pela estrutura dos élitros providos de quatro pares de espinhos longos. Os gêneros que mais se assemelham a Icublabia são Anhanga Galileo \& Martins, 2003 e Blabia Thomson, 1864.

Anhanga tem espinhos no dorso do pronoto e protórax sem espinhos laterais; os élitros sem espinhos e desarmados nos ápices, são bastante distintos dos de Icublabia. Em Blabia, embora existam espécies com espinho nos lados do protórax, não se encontram espécies com espinhos desenvolvidos nos élitros.

Agradecimentos. Ao Dr. Miguel A. Monné (MNRJ) e Dr. Robert Anderson (CMNO), pelo empréstimo de material. A Rejane Rosa (MCNZ) pela ilustração de Icublabia. A Antonio Santos Silva (MZSP) pela execução das fotografias.

\section{REFERÊNCIAS BIBLIOGRÁFICAS}

Bates, H. W. 1866. Contributions to an Insect Fauna of the Amazons Valley. Coleoptera: Longicornes. Ann. Mag. nat. Hist., London, (3)17:191-202.

Breuning, S. 1974. Révision des Rhodopinini Américains (Cerambycidae: Lamiinae). Stud. Ent., Petrópolis, 17:1-210.

Galileo, M. H. M. \& Martins, U. R. 1998a. Novas espécies neotropicais de Desmiphorini e revalidação de Esmia turbata (Coleoptera, Cerambycidae, Lamiinae). Iheringia, Sér. Zool., Porto Alegre, (84):33-42.

_.. 1998b. Novo gênero e novas espécies de Lamiinae (Coleoptera, Cerambycidae) neotropicais. Revta bras. Ent., São Paulo, 42(3/4):147-153.

__. 1999. Sobre espécies de Lamiinae (Coleoptera, Cerambycidae) da Colômbia e do Brasil com garras tarsais divaricadas. Papéis Avuls Zool., São Paulo, 41(6):83-104.

Martins, U. R. \& Galileo, M. H. M. 1994. Revisão do gênero Stereomerus Melzer, 1934 (Coleoptera, Cerambycidae, Lamiinae, Desmiphorini). Papéis Avuls Zool., São Paulo, 39(1):1-11.

1997. Revisão dos gêneros Pseudestola Breuning, Estolomimus Breuning e Euestola Breuning (Coleoptera, Cerambycidae, Lamiinae, Desmiphorini. Revta bras. Zool., Curitiba, 14(1):99-112.

1998. Gêneros sul-americanos de Desmiphorini (Coleoptera, Cerambycidae) com lados do protórax desarmados. Revta bras. Ent., São Paulo, 41(2-4):257-265.

2002. Desmiphorini (Coleoptera, Cerambycidae): novas espécies, nova sinonímia e redescrição de Inermestoloides praeapicealba Breuning, 1942. Papéis Avuls Zool., São Paulo, 42(1):1-12.

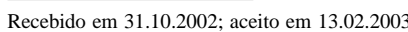

